Sharif University of Technology
Scientia Iranica
SCIENTIA
I RAN I CA

\title{
Estimation of scour downstream of a ski-jump bucket using the multivariate adaptive regression splines
}

\author{
A.H. Haghiabi* \\ Department of Water Engineering, Lorestan University, Khorramabad, Iran.
}

Received 11 August 2015; received in revised form 10 April 2016; accepted 22 August 2016

\section{KEYWORDS}

Energy dissipation; Soft computing;

Hydraulic structure;

Scour depth;

Spillways.

\begin{abstract}
In this paper, modeling the scour downstream of a flip bucket of spillways was considered using empirical formulas, soft computing techniques such as multilayer perceptron (MLP) neural network, and Multivariate Adaptive Regression Splines (MARS). For this purpose, 95 data sets were collected with regard to the most affective parameters on the scouring phenomena at downstream of spillways. During the MLP model development, it was found that the two transfer functions, such as log-sigmoid and radial basis, had very suitable performances for predicting the desired scouring phenomena. The results of MARS model showed that this model with coefficient of determination 0.99 and 0.91 during the development and testing stages, respectively, had suitable performance for modeling the scouring depth at downstream of flip bucket structure. The results of gamma test and MARS model indicated that $q /\left(g d_{w}^{3}\right), R / d_{w}$, and $H / d_{w}$ were the most affective parameters on the scouring phenomena.

(C) 2017 Sharif University of Technology. All rights reserved.
\end{abstract}

\section{Introduction}

Modeling the interaction between the flow and structure is the main part of hydraulic engineering studies. Among the hydraulic structures, spillways are common and important structures used in most of water engineering projects, especially in the high-head dam projects. The main hazards related to the spillways are the cavitation and scouring. Most of the time, in high-head dams projects, velocity of flow through the spillway's chute is more than $20(\mathrm{~m} / \mathrm{s})$. Increasing the velocity of flow through the chute causes a decrease in the pressure, and consequently causes an increase in the probability of cavitation occurrences [1]. By constructing a hydraulic laboratory scaled model, hydraulic engineers usually study the potential of cavitation occurrence through all parts of spillway structure [2]. Another approach for assessing the portability of cavitation occurrence is using the Computational Fluid Dy-

*. E-mail address: ahaghiabi@gmail.com namic (CFD) techniques [3]. In the CFD field, the governing equations which are Navier-stokes ones are coupled with turbulence models, such as Prandtl's mixinglength, k-epsilon, renormalized K-epsilon (RNG), and are numerically solved using the powerful methods such as finite volume, finite element, etc. [4]. Therefore, the probability of occurrence of cavitation can be removed by controlling the hydraulic design criteria. Recently, suitable free or commercial software packages, such as fluent, Flow 3D, and OpenFOAM, are provided. Another hazard related to the spillways is scouring. Souring the riverbed at downstream or under the spillways sometimes causes dam distortion. So, it is necessary to check the scouring phenomena around the spillways; this is more important specifically in the big dam projects $[5,6]$. In the dam projects in which the dam is very high, i.e. in dam projects where the flow velocity though the chute spillways is more than $20(\mathrm{~m} / \mathrm{s})$, the flip bucket structure is used for energy dissipation instance of other types of energy dissipation structure such as stilling basin. Several experimental studies 
have been conducted on the scouring phenomenon at downstream of flip bucket. In this regard, the studies conducted by USBR can be stated. The USBR conducted an extensive study on the scouring depth at downstream of flip bucket and proposed empirical formula for calculating the depth of scour [7,8]. Azmathullah et al. [9] assessed the accuracy of USBR formula for calculating the depth of scour at downstream of spillway of Rana Pratap Sagar Dam which was constructed across the Chamba River, and found that calculating the scour depth using the USBR formula is equal to $30 \mathrm{~m}$, whereas the measured data is equal to $24.7 \mathrm{~m}$. In other words, using the USBR formula causes about 30 percent error for predicting the scour depth. After USBR, several empirical studies have been conducted on the scour depth of calculation at the downstream of flip bucket structure. Kumar and Sreeja [10] assessed the accuracy of the most popular empirical formulas proposed for calculating the scour depth at the downstream of flip bucket, and founded that all these empirical formulas are not reliable for predicting the scour depth. Due to high cost of experiments and deficiency in laboratory studies due to simplifications and limit range of measured parameters, researchers attempt to use the mathematical approaches for modeling and predicting the scour depth at downstream of flip buckets. In the field of mathematical modeling, using both of CFD and soft computing techniques was reported by Xiao et al. [11].Nowadays, by advancing the soft computing techniques in the most areas related to hydraulic engineering, investigators have tried to use these techniques for predicting the scouring phenomena [12-19], specifically scour depth at downstream of flip bucket. In this regard, using the Artificial Neural Networks (ANNs), Genetic Programming (GP), Support Vector machine and M5 Model Tree, Group Method of Data Handling (GMDH), and Adaptive Neuro Fuzzy Inference System (ANFIS) can be mentioned [20-32]. Based on the reports, the precision of all the soft computing techniques was much more than the empirical formulas. In this paper, the Multivariate Adaptive Regression Splines (MARS), as a novel and powerful approach in the field of soft computing, are used for predicting the scour depth at downstream of flip buckets; in the following, a comparison was conducted with empirical formulas and multilayer perceptron (MLP) neural network model. The MARS model was developed by Friedman [33] and has been successfully applied up to now for predicting the river discharge forecasting, rainfall-runoff modeling, etc. [34-36].

\section{Method and materials}

Scouring at the downstream of free surface hydraulic structure is fully complex due to the interaction among flow and structure and sediment of riverbed. So, for

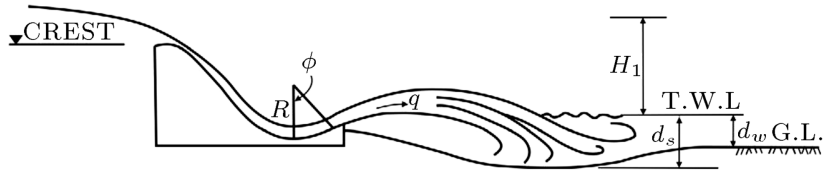

Figure 1. The ski-jump bucket spillway scour [37].

modeling the scour at downstream of hydraulic structure, especially flip bucket structure, the influence parameters should be considered which are posed related to the structure geometry, hydraulic properties of flow and riverbed material. Figure 1 shows a schematic shape of scouring phenomenon at the downstream of flip bucket structure, in which $H_{1}$ is the falling height, $R$ is the flip bucket radios, $q$ is the flow discharge per width of weir, $\phi$ is the angle of flip bucket lip, T.W.L is the tail water elevation, $d_{w}$ is the downstream flow depth, $d_{s}$ is the scouring depth, and G.L is the ground elevation at downstream. The most influence parameters effective in the scouring phenomenon are presented in Eq. (1):

$$
d_{s}=f\left(q, H, R, d_{w}, d_{50}, g, \rho_{w}, \rho_{s}, \phi\right),
$$

where $H$ is the total head (falling height), $d_{50}$ is the mean sediment size, $g$ is the acceleration due to gravity, and $\rho_{w}$ and $\rho_{s}$ are densities of water and sediment. Using the dimensional analysis techniques, such as $\Pi$ theorem, leads to deriving dimensionless parameters whose number is less than the original parameters. Another advantage of applying the dimensional analysis techniques is related to appearance of dimensionless parameters, such as Froude number, not limited to the laboratory conditions. Another advantage of dimensionless parameters is related to the proposition of an optimal form for the experimental formula or soft computing model structure. The resulted dimensionless parameters of $\Pi$ theorem, considering $d_{w}, \rho_{w}$, and $g$ as repeat variables, are presented in Eq. (2) [38]:

$$
\frac{d_{s}}{d_{w}}=f\left(\frac{q}{\sqrt{g d_{w}^{3}}}, \frac{H}{d_{w}}, \frac{R}{d_{w}}, \frac{d_{50}}{d_{w}}, \frac{\rho_{s}}{\rho_{w}}, \phi\right) .
$$

As mentioned in the Introduction Section and with regard to Eqs. (1) and (2), investigators have proposed several empirical formulas for calculating the scour depth at downstream of flip buckets. Table 1 presents a summary of the famous empirical formulas.

As stated in the Introduction Section, the main aim of this study is to develop the MARS model as soft computing techniques for predicting the scour depth at downstream of flip buckets. So, for this purpose, 95 data sets published in the peer-reviewed journal were collected. A summary range of these data is given in Table 2. 
Table 1. Summary of the famous empirical formula proposed for flip bucket scour depth [28].

\begin{tabular}{|c|c|c|}
\hline Row & Author & Equation \\
\hline 1 & Schoklitsch (1932) & $d_{s}=0.521 \frac{q^{0.57} H^{0.2}}{d_{w}^{0.32}}$ \\
\hline 2 & Veronese (1937) & $d_{s}=1.90 q^{0.54} H^{0.225}$ \\
\hline 3 & Kotulas (1967) & $d_{s}=0.78 \frac{q^{0.70} H^{0.35}}{d_{w}^{0.4}}$ \\
\hline 4 & Chee and Kung (1974) & $d_{s}=1.663 \frac{q^{0.60} H^{0.20}}{d_{w}^{0.1}}$ \\
\hline 5 & Martins (1975) & $d_{s}=1.50 q^{0.60} H^{0.10}$ \\
\hline 6 & Machado (1980) & $d_{s}=1.35 \frac{q^{0.50} H^{0.3145}}{d_{w}^{0.0645}}$ \\
\hline 7 & Sofrelec (1980) & $d_{s}=2.30 q^{0.60} H^{0.10}$ \\
\hline 8 & Incyth (1981) & $d_{s}=1.413 q^{0.50} H^{0.25}$ \\
\hline 9 & Mahboobi (1997) & $d_{s}=0.526 \frac{q^{0.645} H^{0.246}}{d^{0.405}}$ \\
\hline 10 & Azar (1998) & $\frac{d_{s}}{H}=1.446\left(\frac{H}{Y_{t}}\right)^{0.739}\left(\frac{q}{d_{50} \sqrt{g H}}\right)_{1}^{0.104\left(\frac{H}{Y_{t}}\right)^{0.475}}$ \\
\hline 11 & Azmathullah (2005) & $\frac{d_{s}}{d_{w}}=6.914\left(\frac{q}{\sqrt{g d_{w}^{3}}}\right)^{0.694}\left(\frac{H}{d_{w}}\right)^{0.0815}\left(\frac{R}{d_{w}}\right)^{0.233}\left(\frac{d_{50}}{d_{w}}\right)^{0.196} \varphi^{0.196}$ \\
\hline
\end{tabular}

Table 2. Summary of range of published data set related to flip bucket scour depth.

\begin{tabular}{ccccccc}
\hline \multirow{2}{*}{ Row } & Parameters & \multirow{2}{*}{ Units } & \multicolumn{4}{c}{ Range } \\
\cline { 4 - 7 } & & Min & Median & Max & S.D. \\
\hline 1 & Unit discharge, $q$ & $\mathrm{~m}^{3} / \mathrm{s} / \mathrm{m}$ & 0.009 & 0.037 & 0.204 & 0.050 \\
2 & Total head, $H$ & $\mathrm{~m}$ & 0.0279 & 0.358 & 1.796 & 0.499 \\
3 & Bucket radius, $R$ & $\mathrm{~m}$ & 0.100 & 0.200 & 0.610 & 0.164 \\
4 & Lip angle, $\Phi$ & $\mathrm{rad}$ & 0.126 & 0.524 & 0.780 & 0.095 \\
5 & Tail water depth, $d_{w}$ & $\mathrm{~m}$ & 0.029 & 0.069 & 0.265 & 0.069 \\
6 & Bed material size, $d_{50}$ & $\mathrm{~m}$ & 0.002 & 0.008 & 0.008 & 0.003 \\
7 & Depth of scour, $d_{s}$ & $\mathrm{~m}$ & 0.051 & 0.185 & 0.550 & 0.104 \\
\hline
\end{tabular}

The performances of each empirical formula, ANN and MARS models, are assessed using the standard error indices such as coefficient of determination (Eq. (3)) and root mean square error (Eq. (4)):

$$
\begin{aligned}
& R^{2}=\left(\frac{\sum_{i=1}^{n}\left(O_{i}-\bar{O}\right)\left(P_{i}-\bar{P}\right)}{\sqrt{\sum_{i=1}^{n}\left(O_{i}-\bar{O}\right)^{2}} \sqrt{\sum_{i=1}^{n}\left(P_{i}-\bar{P}\right)^{2}}}\right)^{2}, \\
& \mathrm{EMSE}=\sqrt{\frac{\sum_{i=1}^{n}\left(R O_{i}-P_{i}\right)^{2}}{n}} .
\end{aligned}
$$

To identify the most affective parameters in the scouring phenomenon, the Gamma Test (GT) technique was used. In the following, to assess the performance of the MARS model in comparison to other soft computing models, the multilayer perceptron (MLP) neural network model as a common type of soft computing technique was developed. At the end, a compression is conducted on the results of the empirical formulas, GT, MLP, and MARS models.

\subsection{Gamma Test (GT)}

The Gamma Test (GT) is a technique for data analysis. This method is used for modeling the data set, i.e. it is applied for modeling the phoneme based on the input and output of the data set. The general form of the data set is present in Eq. (5) [39]:

$$
\left[\left(X_{i}, y_{i}\right), 1 \leq i \leq M\right]
$$

where $X_{i}$ is the vector of input variables, $y_{i}$ is the 
output vectors, and $M$ is the number of the data set. The general form of the relation among the input and output parameters is defined as a function of Eq. (6):

$$
y=f\left(x_{1}, x_{2}, \ldots, x_{d}\right)+r,
$$

where $d$ is the number of input variables, $f$ is the unknown smooth function, and $r$ is the random constant that depicts the noise. The gamma statistics $(\Gamma)$ is a predict of variance of output which cannot be reported with the smooth function. GT is proportional to the number of the nearest neighbor ( $K$ th) for the input parameters. The GT can be extracted with the delta function as in Eq. (7):

$$
\delta_{M}(k)=\frac{1}{M} \sum_{i=1}^{M}\left|X_{i, k}-X_{i}\right|^{2} \quad(1 \leq k \leq p),
$$

where $p$ is proportional to sampling data density. The number of $p$ is derived as a value which produces a minimum value for $\Gamma$. In this study, the value of $p$ is assumed to be equal to 10 . $p$ value can be derived during the try and error process which leads to creation of a minimum value for $\Gamma$. The basic equation used for this purpose is presented in Eq. (8):

$$
\gamma_{M}(k)=\frac{1}{2 M} \sum_{i=1}^{M}\left|y_{N(i, k)}-y_{i}\right|^{2} \quad(1 \leq k \leq p),
$$

where $y_{N(i, k)}$ is the corresponding $y$-value for the $k$ th nearest neighbor of $X_{i}$ in Eq. (4). For computing $\Gamma$, a least squares regression line is constructed for $p$ points $\left(\delta_{M}(k), \gamma_{M}(k)\right)$ as in Eq. (9):

$$
\gamma=A \delta+\Gamma
$$

where $A$ is the gradient. Carrying out a gamma test is a fast procedure, which can provide $\Gamma$ value for each subset of input variables. When the subset's associated $\Gamma$ value is closest to zero, it can be considered as the best combination of input variables. The GT has been applied in different fields of water engineering for deriving the most effective components such as river pollution problems [40], stream flow prediction [41], and evaporation estimation [42].

\subsection{Artificial Neural Networks (ANNs)}

ANN is a nonlinear mathematical model able to simulate many mathematical complexes corresponding to inputs and outputs. Multilayer perceptron networks are common types of ANN that are widely used in studies. To use MLP model, definition of appropriate functions, weights, and bias should be considered. Due to the nature of the problem, different activity functions in neurons can be used. An ANN may have one or more hidden layers. Figure 1 demonstrates a three-layer neural network consisting of inputs layer, hidden layer (layers), and outputs layer. As shown in Figure 2, $w_{i}$ is the weight and $b_{i}$ is the bias for each neuron. Weight and biases' values will be assigned progressively and corrected during training process by comparing the predicted outputs with the known outputs. Such networks are often trained using backpropagation algorithm. In the present study, ANN was trained by Levenberg-Marquardt technique, because this technique is more powerful and faster than the conventional gradient descent technique [43].

\subsection{Multivariate Adaptive Regression Splines (MARS)}

The MARS refer to a novel approach in the field of soft computing which applies a series of simple linear regressions. As mentioned in the Introduction Section, the MARS was introduced by mathematician Friedman [33]. MARS is a high precision technique for modeling the systems based on the data set. This approach separated the computational space into sub ranges of input variables (predicting parameters) and defined the relationship between the input parameters and output variable. In other words, this technique has high ability to characterize the relationship between the independent and dependent variables in each desired phenomenon. This process was carried out by fitting a simple regression into each input parameter for predicting the output. MARS separated the space of inputs parameters into various units, and then fitted a spline function into these units. These elements of the regressions are named as basic function of the MARD methods. One of the main advantages of the MARS

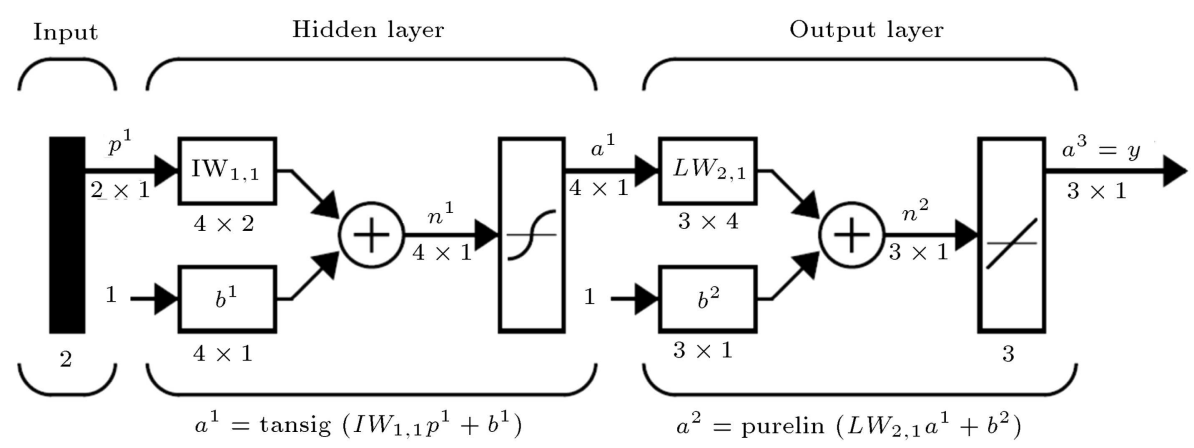

Figure 2. Sketch of three-layer ANN architecture. 
method is highlighting the input parameters with more effect on the output parameter. This method could be used for small and big data sets. A basic function gives information about the relationship between the inputs and output parameters which is defined as:

$$
\begin{aligned}
& h_{m}(x)=\operatorname{Max}(0, C-x) \quad \text { or } \\
& h_{m}(x)=\operatorname{Max}(0, x-C),
\end{aligned}
$$

where $h$ is the basic function, $x$ is the input parameter, $C$ is the threshold value of the independent (input) parameter of $x$. The general form of the MARS is introduced as follows:

$$
Y=f(x)=\beta_{0}+\sum_{m=1}^{M} \beta_{m} h_{m}(x),
$$

where $Y$ is the output parameters, $\beta_{0}$ is the constant value, $M$ is the number of function, $h_{m}(x)$ is the $M$ th basic function, and $\beta_{m}$ is the corresponding coefficient of $h_{m}(x)$. It takes two steps to develop the MARS. At the first step, all the basic functions are prepared. In this step, overfitting may occur; so in the next step, to prevent overfitting, the basic functions, which are of less importance, are pruned with Generalized CrossValidation (GCV) criteria calculated in Eq. (12):

$$
\mathrm{GCV}=\frac{\frac{1}{n} \sum_{i=1}^{n}\left(y_{i}-f\left(x_{i}\right)\right)^{2}}{\left(1-\left(\frac{C(B)}{n}\right)\right)^{2}}
$$

where $n$ denotes the number of observation, and $C(B)($ Eq. (13)) denotes a complexity criterion which increases by the number of basic functions [21]:

$$
C(B)=(B+1)+d B \text {. }
$$

\section{Results and discussion}

The scour depth at the downstream of flip buckets was assessed with regard to the collected data set. In other words, the value of input variables in each empirical formula was chosen with regard to the collected data set. The performance of empirical formula was evaluated by calculating the standard error indices. The results of each empirical formula are plotted versus the observed data as shown in Figure 3. Moreover, In this figure, the error indices are shown. Schoklitsch (1932) with $R^{2}=$ 0.45 and $\mathrm{RMSE}=0.08$ is accurate among the empirical formulas, as shown in this figure, and the poorest performance is related to Azar (1998); as seen, all the empirical formulas have no acceptable performances for practical purposes. The results of assessing the performance of empirical formula support those of the study conducted by Azmathullah et al. [9] who stated that using the empirical formula for calculating the depth of scour has obvious errors compared to the measured data.

\subsection{Gamma test}

In this study, to define the most important affective parameters on the scour at downstream of flip bucket, seven scenarios were considered. In the following, these scenarios were analyzed using the gamma test. The scenarios were considered with regard to Eq. (2). Scenario number 1 in Table 3 at row number 1 contains all the input parameters. In the following, to define the most important parameters, one of the input parameters was removed in GT analysis. This process is continued to define the importance of each input parameter. The results of GT analysis are presented in Table 3. The GT parameters, such as gamma, gradient, standard error, and V-ratio, were chosen as the criteria for defining the most important parameters. The scenario with the minimum value for the GT parameters shows the most affective influence of input parameters on the output parameter. The variation of $\mathrm{V}$-ratio is between 0 and 1 . This point is notable in that this factor is close to zero which shows that the related scenario could accurately predict the output regarding the related input parameters.

Reviewing Table 3, it is clear that scenario number 1, which involves the total input variables, has minimum value for the GT parameters. Table 3 shows that removing parameters $q /\left(g d_{w}^{3}\right)$ and $R / d_{w}$ causes a

Table 3. Results of gamma test analysis test.

\begin{tabular}{cccccc}
\hline Row & Inputs & Gammas & Gradient & Standard error & V-ratio \\
\hline 1 & All & 0.0009 & 0.139 & 0.010 & 0.004 \\
2 & All- $q /\left(g d_{w}^{3}\right)$ & 0.060 & 0.054 & 0.030 & 0.243 \\
3 & All- $H / d_{w}$ & 0.0096 & 0.138 & 0.007 & 0.039 \\
4 & All- $R / d_{w}$ & 0.0286 & 0.126 & 0.030 & 0.114 \\
5 & All- $d_{50} / d_{w}$ & 0.0033 & 0.129 & 0.008 & 0.013 \\
6 & All- $\rho_{s} / \rho_{w}$ & 0.0009 & 0.139 & 0.010 & 0.004 \\
7 & All- $\phi$ & 0.0005 & 0.197 & 0.0096 & 0.002 \\
\hline
\end{tabular}



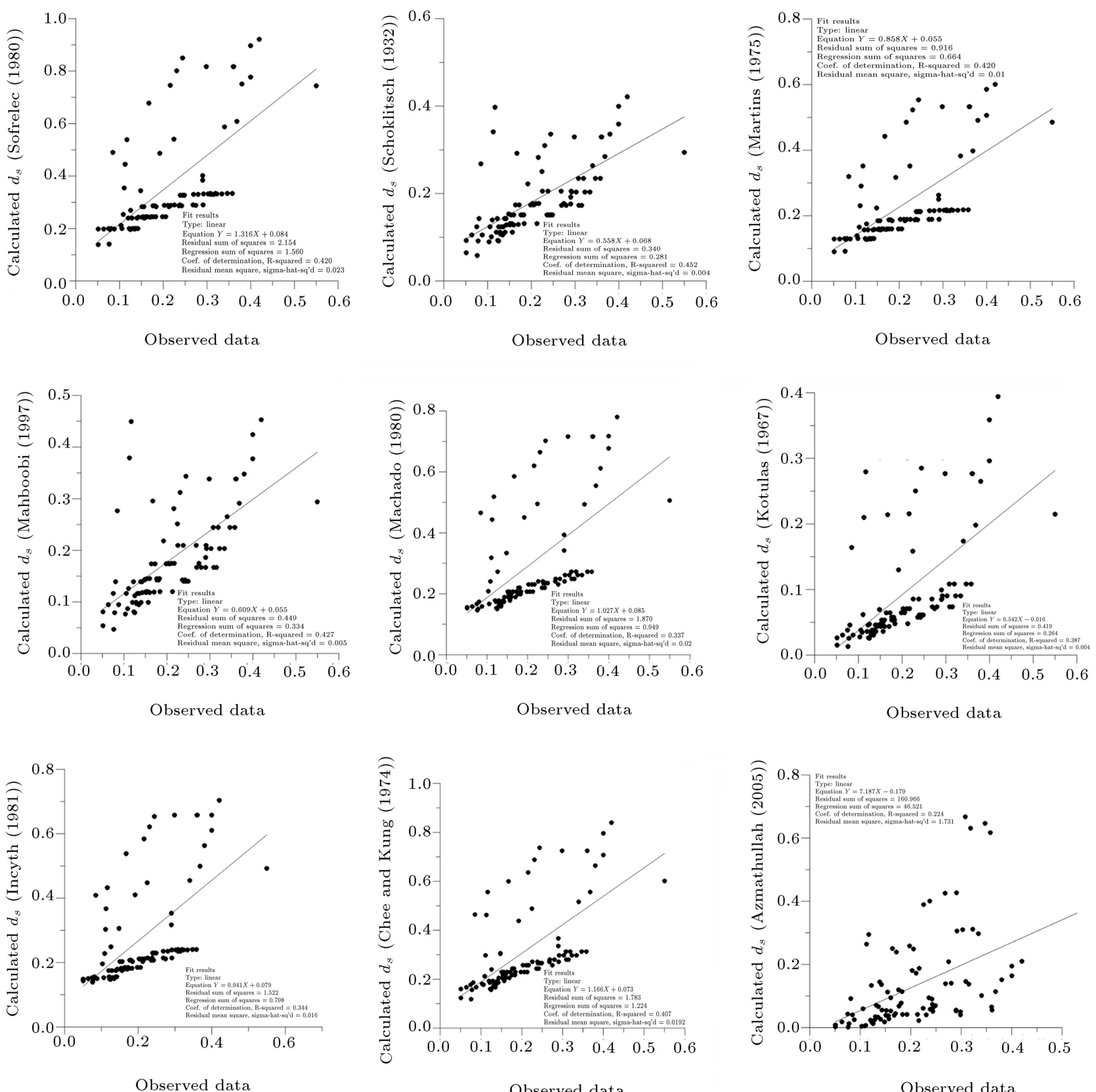

Observed data

Observed data
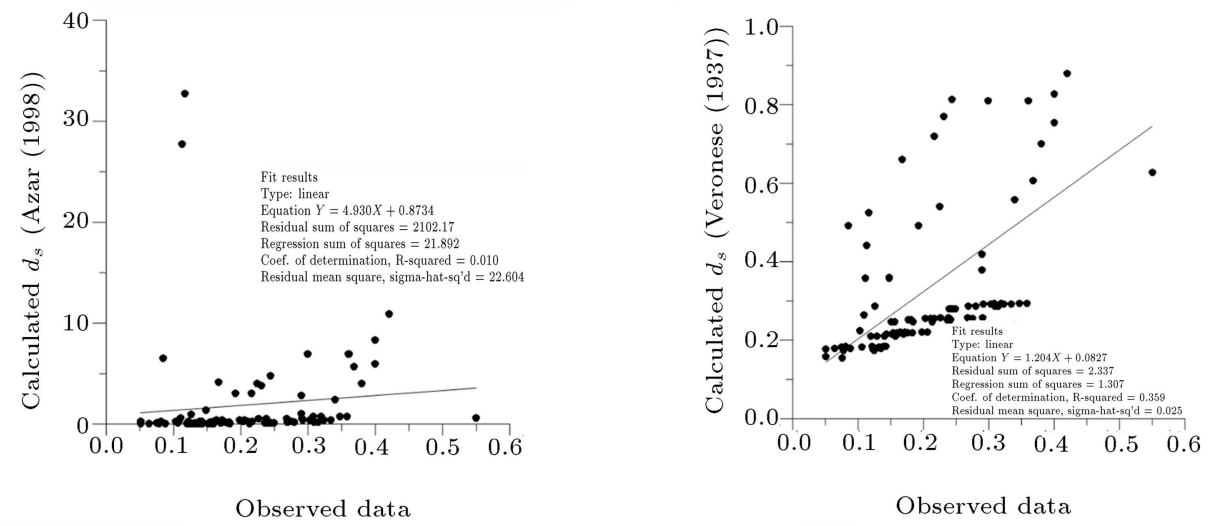

Figure 3. The performance of empirical formula for calculating the depth of scour at downstream of a ski-jump bucket. 


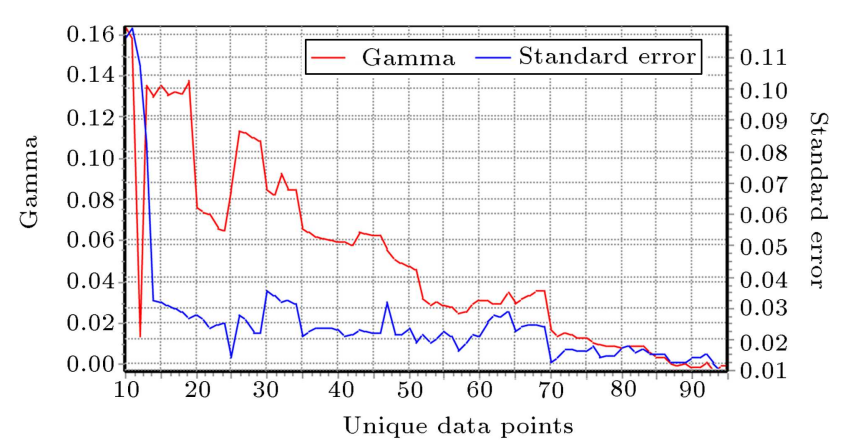

Figure 4. The variation of gamma static and standard error with unique data points.

significant increase in the gamma value, so it is found that these parameters are the most important parameters of the scouring depth. The variation of gamma and standard error values for the data set is shown in Figure 4, where the standard error curve and gamma curve meet at point 80 . It means that for modeling the scouring depth with regard to the collected data set, qualification of 80 data sets is enough.

\subsection{Artificial neural network results}

Developing the Artificial Neural Network (ANN) models, as popular representative of soft computing techniques, is based on the data set. So, for this purpose, the collected data set is divided into two groups as training and testing data sets. Data selections for training and testing process the ANNs model carried out by random approach. The percent of each group portfolio from the total data set will be determined during the model preparation. The input parameters were chosen with regard to Eq. (2); in other words, $q / \sqrt{g d_{w}^{3}}, H / d_{w}, R / d_{w}, d_{50} / d_{w}$, and $\phi$ were chosen as input variables, and $d_{s} / d_{w}$ was considered as output parameter. Designing the structure of ANNs model is almost based on the designer experience, whereas recommendation of investigators who conducted similar research is useful. Designing the ANNs model includes the types of the neural network model, such as multilayer perceptron, support vector machine radial basis function, etc., number of the hidden layer(s), number of the neurons in each layer, defining the suitable transfer function for the neurons of hidden and output layers and learning algorithm. In this study, to assess the performance of ANNs models for modeling the scouring depth at the downstream of flip buckets, two models, such as multilayer perceptron (MLP) and Radial Basis Function (RBF) model, were applied. As mentioned in the past section, preparation of ANNs model included the number of the hidden layer, number of the neuron in each layer, type of the transfer function, and learning method. To obtain an optimal structure for the ANNs model, firstly, one hidden layer was considered; in the following, the number of the neurons in the hidden layer was increased one by one, and various types of transfer function, such as Radial Basis Function (RBF), logsigmoid transfer (logsig), hyperbolic tangent sigmoid transfer (tansig), linear transfer function(purelin), etc., were tested. For developing the ANNs model, the Matlab software utilities were applied. During the ANNs models' development, it was found that the two transfer functions, RBF and logsig, have very suitable performance among the other type of transfer functions. The Levenberg-Marquardt technique was used for ANNs model learning. Table 4 presents a summary of try-and-error process conducted to define the ANNs models with very suitable performance for predicting the scour depth at the downstream of flip bucket of spillway.

As seen in Table 4, the MLP model, which contained ten neurons with logsig and radbas as transfer functions, has suitable performance to model the scour depth. During the ANNs model development, it was found that the increase of the number of neurons in the first hidden layer and adding the number of the hidden layer have no significant effect on the increasing performance of the model. During the ANNs model preparation, it was also found that increasing the number of the neurons causes a decrease in the ANNs model performances. As seen in Table 4, adding four neurons to the existing ones in the first hidden layer

Table 4. The performance and summary of the MLP model during the development stage.

\begin{tabular}{|c|c|c|c|c|c|c|c|c|c|c|}
\hline \multirow[t]{2}{*}{ Row } & \multirow[t]{2}{*}{ N-H-L } & \multirow[t]{2}{*}{ F-HL \& TF } & \multirow[t]{2}{*}{ S-HL \& TF } & \multirow[t]{2}{*}{ Out-layer } & \multicolumn{3}{|c|}{ Train } & \multicolumn{3}{|c|}{ Test } \\
\hline & & & & & $R^{2}$ & MSE & RMSE & $R^{2}$ & MSE & RMSE \\
\hline 1 & 1 & 6-logsig & - & 1-purelin & 0.99 & 0.08 & 0.29 & 0.99 & 0.11 & 0.33 \\
\hline 2 & 1 & 10-logsig & - & 1-purelin & 0.99 & 0.05 & 0.23 & 0.83 & 0.98 & 0.99 \\
\hline 3 & 1 & 6-radbas & - & 1-purelin & 0.97 & 0.21 & 0.46 & 0.60 & 2.01 & 1.42 \\
\hline 4 & 1 & 10-radbas & - & 1-purelin & 0.99 & 0.017 & 0.13 & 0.99 & 0.06 & 0.25 \\
\hline
\end{tabular}

Note: N-H-L: Number of Hidden Layer, F-HL \& TF: First Hidden Layer \& Transfer Function,

S-HL \& TF: Second Hidden Layer \& Transfer Function. 


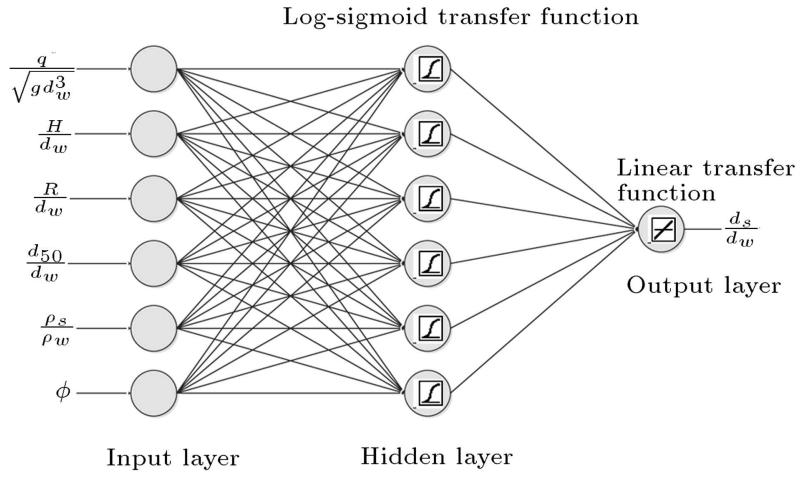

Figure 5. The structure of developed MLP model with logsig function.

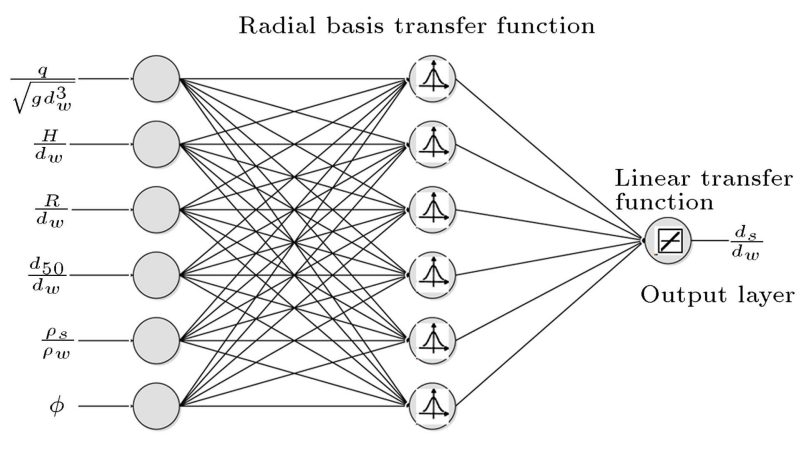

Input layer Hidden layer

Figure 6. The structure of developed MLP model with radial basis function.

due to data number limitation causes a decrease in the model performance at the testing stage. The structure of the two ANNs model is shown in Figures 5 and 6 .

The performance of the two ANNs models during the training and testing stages is shown in Figures 7 to 10. As seen in these figures, the minimum error indices are equal to $R^{2}=0.95$ and $\mathrm{RMSE}=0.44$, and these correspond to the RBF transfer function. In these figures, the results of the ANNS models during the training and testing stages are plotted together and compared with the observed data. To present more information about the ANNs models' performances, the error distribution for the training and testing data sets is also plotted. Moreover, the histogram of error is plotted to define the density of error. Evaluating the error histogram shows that most error values are concentrated around the zero.

\subsection{Result of MARS model}

Preparation of the MARS model as similar to other type of soft computing models is based on the data set. For this purpose, collected data set with regard to the GT results (Figure 4) and Eq. (2) was randomly divided into two groups of training and testing. $85 \%$ of the total data were considered for training and others (15\%) for testing group. During the MARS model development, at the first step, 25 basic functions were considered, and at the second step (pruning step), seven basic functions were pruned. At the end, the optimal MARS model with 18 basic functions was derived. The general form of the obtained model MARS is given in Eq. (14):

$$
d_{s} / d_{w}=-6.006+\sum_{m=1}^{12} \beta_{m} h_{m}(x) .
$$

The extended form of the MARS model is given in Table 5 .

$$
\begin{aligned}
& \text { Note }: x 1: \frac{q}{\sqrt{g d_{w}^{3}}}, \quad x 2: \frac{H}{d_{w}}, \\
& x 3: \frac{R}{d_{w}}, \quad x 4: \frac{d_{50}}{d_{w}}, \\
& x 5: \frac{\rho_{s}}{\rho_{w}}, \quad x 6: \phi .
\end{aligned}
$$

Eq. (10) can be used for predicting the scour depth of a downstream of flip bucket. As seen in Table 5, $\frac{q}{\sqrt{g d_{w}^{3}}}, \frac{H}{d_{w}}$, and $\frac{R}{d_{w}}$ have appeared in almost all of the basic functions. It means that these three parameters, in comparison to the other parameters, are more
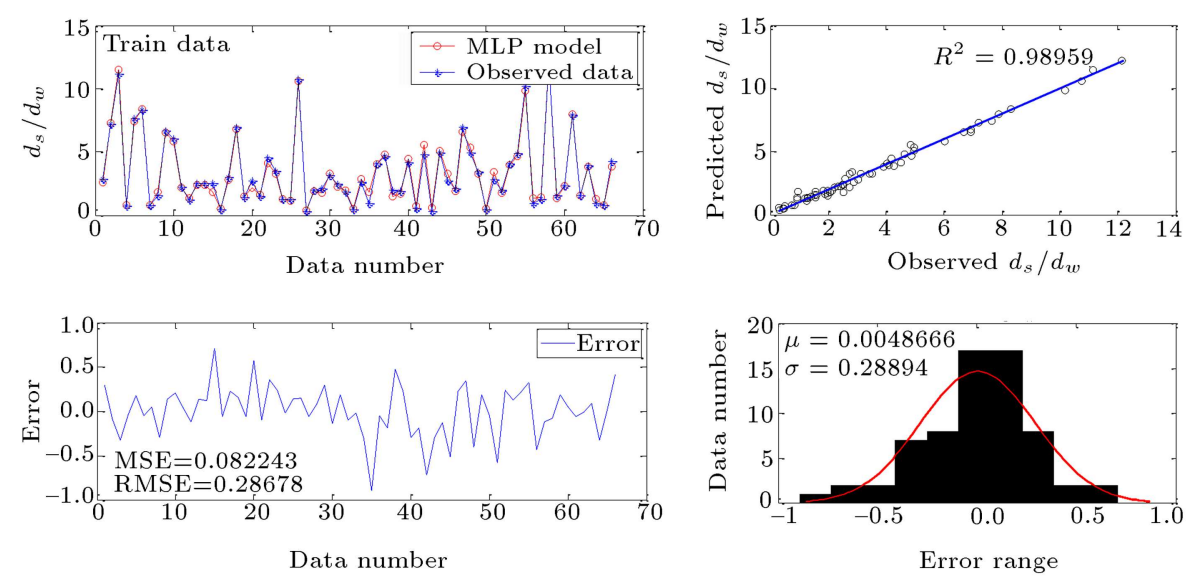

Figure 7. The performance of developed MLP model during the training stage with logsig function. 

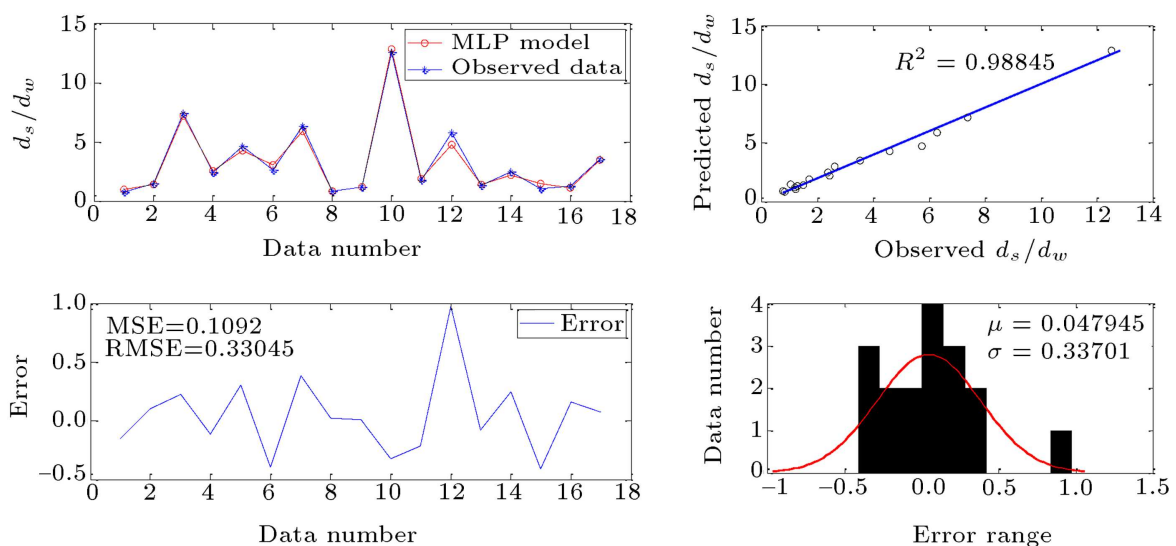

Figure 8. The performance of developed MLP model during the testing stage with logsig function.
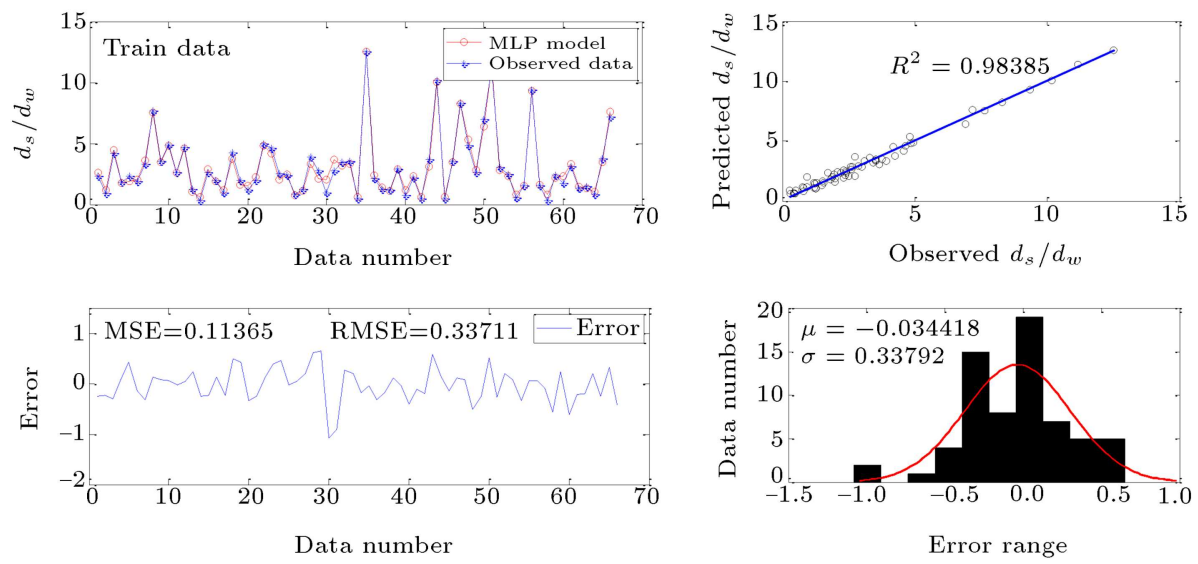

Figure 9. The performance of developed MLP model during the training stage with radial basis function.
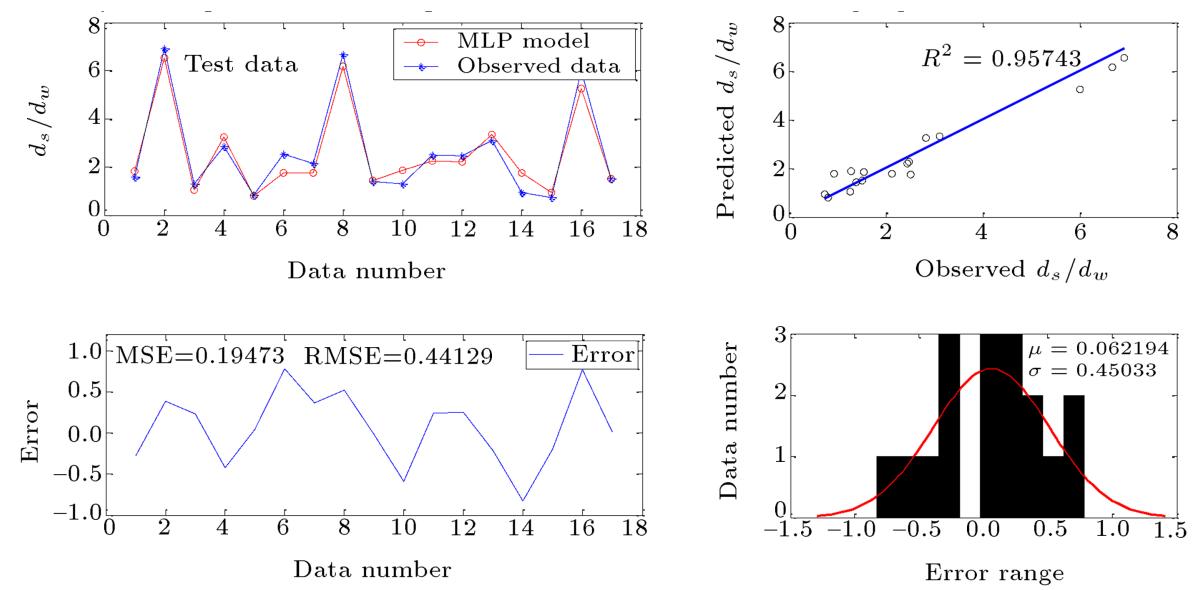

Figure 10. The performance of developed MLP model during the testing stage with radial basis function.

effective in the scour depth. This result from the MARS model upholds the results of the MLP model of sensitivity analysis and GT. Moreover, the performance of the MARS model during the development process (training and testing stages) is given in Figures 11 and 12, where the MARS model along and versus the observed data is plotted. Moreover, the results of error indices calculation appear in these figures; as seen, the performance of the MARS model for predicting the scour depth is so suitable, specifically when compared to the empirical formulas.

\subsubsection{Comparing the results with those of the previous studies}

In this section, the results of the MARS model are compared with those of other soft computing tech- 
Table 5. The basic function and the related coefficient of the MARS model.

\begin{tabular}{cll}
\hline Basic function & \multicolumn{1}{c}{ Equation } & \multicolumn{1}{c}{ Coefficient $\boldsymbol{\beta}_{\boldsymbol{m}}$} \\
\hline$h_{1}(x)$ & $B F 1=\max (0,1.646-x 1)$ & -1.215 \\
$h_{2}(x)$ & $B F 2=\max (0, x 2-12.255)$ & -218.871 \\
$h_{3}(x)$ & $B F 3=\max (0, x 4-0.08)$ & 144.525 \\
$h_{4}(x)$ & $B F 4=\max (0,0.08-x 4)$ & 46.537 \\
$h_{5}(x)$ & $B F 5=B F 1 * \max (0,0.08-x 4)$ & -6.674 \\
$h_{6}(x)$ & $B F 6=\max (0, x 3-3.204) * \max (0,0.611-x 6)$ & 3.207 \\
$h_{7}(x)$ & $B F 7=\max (0,3.204-x 3) * \max (0, x 4-0.011)$ & -0.146 \\
$h_{8}(x)$ & $B F 8=\max (0,12.255-x 2) * \max (0,0.835-x 1)$ & 4.067 \\
$h_{9}(x)$ & $B F 9=B F 4 * \max (0,7.536-x 2)$ & 22.715 \\
$h_{10}(x)$ & $B F 10=\max (0,12.255-x 2) * \max (0, x 4-0.0137)$ & -49.226 \\
$h_{11}(x)$ & $B F 11=\max (0,12.255-x 2) * \max (0,0.0137-x 4)$ & 22.906 \\
$h_{12}(x)$ & $B F 12=\max (0, x 4-0.0137) * \max (0, x 2-3.015)$ & -1.215 \\
\hline
\end{tabular}

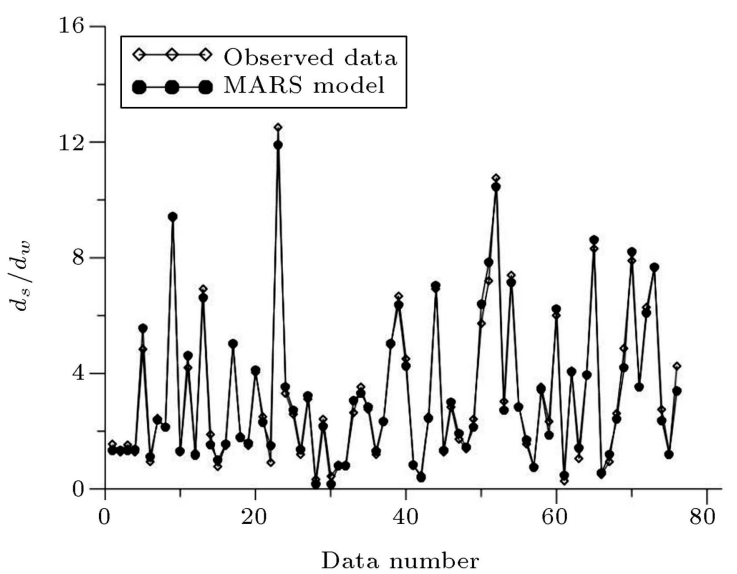

(a)

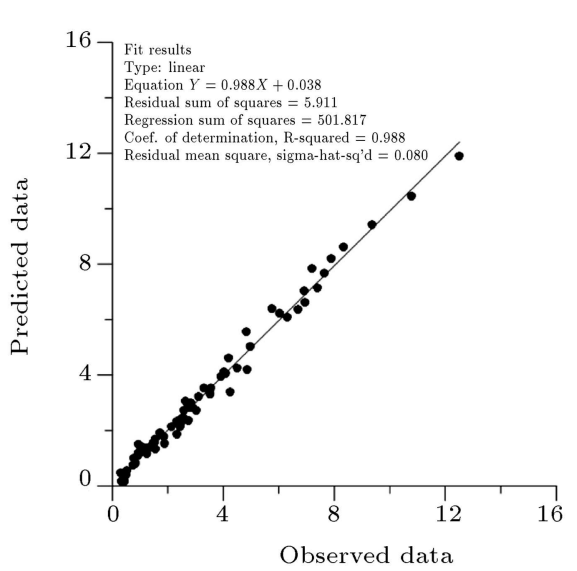

(b)

Figure 11. The performance of MARS model during the development stage.

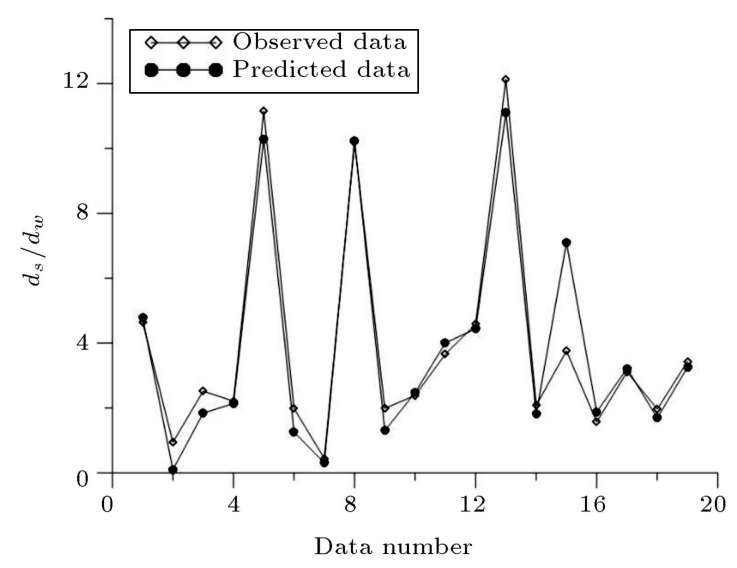

(a)

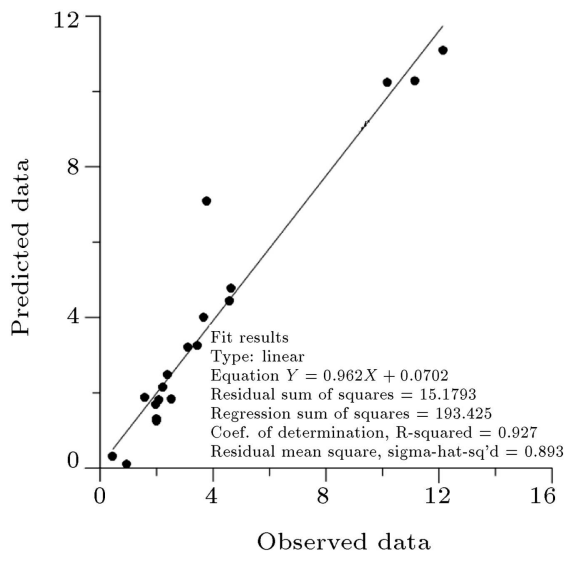

(b)

Figure 12. The performance of MARS model during the testing stage.

nique implemented for predicting the scouring depth at downstream of ski-jump bucket. Goyal and Ojha [27] developed the ANN, SVM, and M5 Model Tree for predicting the scour depth at downstream of ski-jump bucket. They considered various scenarios with regard to the affective parameters during the development of mentioned soft computing techniques. They found that when all affective parameters are considered as input parameters, the ANN is more accurate. They evaluated the performance of soft computing techniques in the absence of other affective parameters, and found that the SVM is more accurate. The results of developed MLP in this study also showed that the performance of MLP model with regard to the all input effective pa- 
rameters is very suitable. Noori and Hooshyaripor [28] developed the ANN model based on the most effective input parameters, and found that the log-sigmoid has suitable performance for modeling the scour depth at downstream of ski-jump bucket, and also Azmathullah et al. [9] found that the radial basis function has suitable performance for modeling the scour depth. Najafzadeh et al. [37] developed the GMDH model to predict the scour depth, and found that $\varphi$ and $H_{1} / d_{w}$ are more important parameters for predicting scour hole geometry. The results of these studies uphold those of GT and MARS models conducted on this study.

\section{Conclusion}

Scouring at downstream of hydraulic structures is one of the main hazards discussed in the field of safety factor analysis. Among the hydraulic structures, spillways are the most important structures, specifically in the big dam projects. In the high-head dam projects, flip buckets are used for energy dissipation. Scouring at downstream of this structure is one of the flip buckets in the main hazard related to the high-head dam projects. Recently, by advancing the soft computing techniques in most areas, especially in the water engineering, using these models has been applied to predict the scouring phenomena. Today, the new soft computing models, such as Multivariate Adaptive Regression Splines (MARS), have been proposed for modeling the complex systems based on the input and output data set. The results of this study showed that the MARS model has high precision for modeling the scouring depth at downstream of flip buckets. The main utilities of the MARS model are related to give clear information about internal process carried out in the development process model. Another utility of the MARS model is related to programing its results for another purpose.

\section{References}

1. Dehdar-behbahani, S. and Parsaie, A. "Numerical modeling of flow pattern in dam spillway's guide wall. Case study: Balaroud dam, Iran", Alexandria Engineering Journal, 55(1), pp. 467-473 (2016).

2. Hager, W.H. and Pfister, M. "Hydraulic modelling - an introduction: Principles, methods and applications", Journal of Hydraulic Research, 48(4), pp. 557-558 (2010).

3. Parsaie, A., Haghiabi, A.H. and Moradinejad, A. "CFD modeling of flow pattern in spillway's approach channel", Sustainable Water Resources Management, 1(3), pp. 245-251 (2015).

4. Chinnarasri, C., Kositgittiwong, D. and Julien, P.Y. "Model of flow over spillways by computational fluid dynamics", Proceedings of the Institution of Civil Engineers - Water Management, 167(3), pp. 164-175 (2014).
5. Muzzammil, M. and Siddiqui, N.A. "Reliability analysis of scour downstream of a ski-jump bucket", Proceedings of the Institution of Civil Engineers - Water Management, 162(6), pp. 389-398 (2009).

6. Zhang, H. and Zhang, X. "Numerical simulation of ski-jump jet motion using lattice Boltzmann method", Science China Technological Sciences, 54(1), pp. 72-75 (2011).

7. Heller, V., Hager, W.H. and Minor, H.-E. "Ski jump hydraulics", Journal of Hydraulic Engineering, 131(5), pp. $347-355$ (2005).

8. Dargahi, B. "Scour development downstream of a spillway", Journal of Hydraulic Research, 41(4), pp. 417-426 (2003).

9. Azmathullah, H.M., Deo, M.C. and Deolalikar, P.B. "Neural networks for estimation of scour downstream of a ski-jump bucket", Journal of Hydraulic Engineering, 131(10), pp. 898-908 (2005).

10. Kumar, C. and Sreeja, P. "Evaluation of selected equations for predicting scour at downstream of ski-jump spillway using laboratory and field data", Engineering Geology, 129-130, pp. 98-103 (2012).

11. Xiao, Y., Wang, Z., Zeng, J., Zheng, J., Lin, J. and Zhang, L. "Prototype and numerical studies of interference characteristics of two ski-jump jets from opening spillway gates", Engineering Computations, 32(2), pp. 289-307 (2015).

12. Najafzadeh, M. "Neuro-fuzzy GMDH based particle swarm optimization for prediction of scour depth at downstream of grade control structures", Engineering Science and Technology, an International Journal, 18(1), pp. 42-51 (2015).

13. Najafzadeh, M. and Lim, S.Y. "Application of improved neuro-fuzzy GMDH to predict scour depth at sluice gates", Earth Science Informatics, 8(1), pp. 187196 (2015).

14. Najafzadeh, M. "Neuro-fuzzy GMDH systems based evolutionary algorithms to predict scour pile groups in clear water conditions", Ocean Engineering, 99, pp. 85-94 (2015).

15. Azamathulla, H.M., Haghiabi, A.H. and Parsaie, A. "Prediction of side weir discharge coefficient by support vector machine technique", Water Science and Technology: Water Supply, 16(4), pp. 1002-1016 (2016). DOI:10.2166/ws.2016.014.

16. Parsaie, A. "Predictive modeling the side weir discharge coefficient using neural network", Modeling Earth Systems and Environment, 2(2), pp. 1-11 (2016).

17. Parsaie, A. and Haghiabi, A.H. "Predicting the longitudinal dispersion coefficient by radial basis function neural network", Modeling Earth Systems and Environment, 1(4), pp. 1-8 (2015).

18. Parsaie, A. and Haghiabi, A.H. "Prediction of discharge coefficient of side weir using adaptive neurofuzzy inference system", Sustainable Water Resources Management, pp. 1-8 (2016). DOI:10.1007/s40899-0160055-6. In press 
19. Parsaie, A., Haghiabi, A.H., Saneie, M. and Torabi, H. "Prediction of energy dissipation on the stepped spillway using the multivariate adaptive regression splines", ISH Journal of Hydraulic Engineering, 22(3), pp. 281-292 (2016).

20. Ayoubloo, M.K., Azamathulla, H.M., Ahmad, Z., Ghani, A.A., Mahjoobi, J. and Rasekh, A. "Prediction of scour depth in downstream of ski-jump spillways using soft computing techniques", International Journal of Computers and Applications, 33(1), pp. 92-97 (2011).

21. Samadi, M., Jabbari, E., Azamathulla, H.M. and Mojallal, M. "Estimation of scour depth below free overfall spillways using multivariate adaptive regression splines and artificial neural networks", Engineering Applications of Computational Fluid Mechanics, 9(1), pp. 291$300(2015)$.

22. Najafzadeh, M. and Azamathulla, H.M. "Neuro-Fuzzy GMDH to predict the scour pile groups due to waves", Journal of Computing in Civil Engineering, 29(5), pp. 04014068 (2015).

23. Azamathulla, H.M. and Ghani, A.A. "Genetic programming for predicting longitudinal dispersion coefficients in streams", Water Resour Manage, 25(6), pp. 1537-1544 (2011).

24. Azamathulla, H.M., Ghani, A.A. and Zakaria, N.A. "ANFIS-based approach to predicting scour location of spillway", Proceedings of the Institution of Civil Engineers - Water Management, 162(6), pp. 399-407 (2009).

25. Azamathulla, H.M., Deo, M.C. and Deolalikar, P.B. "Alternative neural networks to estimate the scour below spillways", Advances in Engineering Software, 39(8), pp. 689-698 (2008).

26. Azamathulla, M.H., Ghani, A.A., Zakaria, N.A., Lai, S.H., Chang, C. K., Leow, C.S. and Abuhasan, Z. "Genetic programming to predict ski-jump bucket spill-way scour", Journal of Hydrodynamics, Ser. B, 20(4), pp. 477-484 (2008).

27. Goyal, M.K. and Ojha, C.S.P. "Estimation of scour downstream of a ski-jump bucket using support vector and M5 model tree", Water Resources Management, 25(9), pp. 2177-2195 (2011).

28. Noori, R. and Hooshyaripor, F. "Effective prediction of scour downstream of ski-jump buckets using artificial neural networks", Water Resources, 41(1), pp. 8-18 (2014).

29. Azamathulla, H.M. "Gene expression programming for prediction of scour depth downstream of sills", Journal of Hydrology, 460-461, pp. 156-159 (2012).

30. Najafzadeh, M., Etemad-Shahidi, A. and Lim, S.Y. "Scour prediction in long contractions using ANFIS and SVM", Ocean Engineering, 111, pp. 128-135 (2016).
31. Najafzadeh, M. and Bonakdari, H. "Application of a neuro-fuzzy GMDH model for predicting the velocity at limit of deposition in storm sewers", Journal of Pipeline Systems Engineering and Practice, 8(1), p. 06016003 (2017). DOI:10.1061/(asce)ps.

32. Friedman, J.H. " Multivariate adaptive regression splines", The Annals of Statistics, pp. 1-67 (1991).

33. Samadi, M., Jabbari, E., Azamathulla, H.M. and Mojallal, M. "Estimation of scour depth below free overfall spillways using multivariate adaptive regression splines and artificial neural networks", Engineering Applications of Computational Fluid Mechanics, 9(1), pp. 291$300(2015)$.

34. Sharda, V.N., Prasher, S.O., Patel, R.M., Ojasvi, P.R. and Prakash, C. "Performance of Multivariate Adaptive Regression Splines (MARS) in predicting runoff in mid-Himalayan micro-watersheds with limited data" [Performances de régressions par splines multiples et adaptives (MARS) pour la prévision d'écoulement au sein de micro-bassins versants Himalayens d'altitudes intermédiaires avec peu de données], Hydrological Sciences Journal, 53(6), pp. 1165-1175 (2008).

35. Zhang, W. and Goh, A.T.C. "Multivariate adaptive regression splines and neural network models for prediction of pile drivability", Geoscience Frontiers, 7(1), pp. 45-52 (2016).

36. Najafzadeh, M., Barani, G.-A. and Hessami-Kermani, M.-R. "Group method of data handling to predict scour at downstream of a ski-jump bucket spillway", Earth Science Informatics, 7(4), pp. 231-248 (2014).

37. Naghikhani, A., Noori, R., Sheikhian, H. and Ghiasi, B. "Estimating scour hole dimensions of ski jump downstream of dams using granular computing model", Journal of Hydraulics, 9(3), pp. 45-60 (2015).

38. Noori, R., Karbassi, A. and Salman Sabahi, M. "Evaluation of PCA and Gamma test techniques on ANN operation for weekly solid waste prediction", Journal of Environmental Management, 91(3), pp. 767-771 (2010).

39. Noori, R., Deng, Z., Kiaghadi, A. and Kachoosangi, F.T. "How reliable are ANN, ANFIS, and SVM techniques for predicting longitudinal dispersion coefficient in natural rivers?", Journal of Hydraulic Engineering, $142(1)$, p. 04015039 (2016).

40. Noori, R., Karbassi, A.R., Moghaddamnia, A., Han, D., Zokaei-Ashtiani, M.H., Farokhnia, A. and Gousheh, M.G. "Assessment of input variables determination on the SVM model performance using PCA, Gamma test, and forward selection techniques for monthly stream flow prediction", Journal of Hydrology, 401(3-4), pp. 177-189 (2011). 
41. Moghaddamnia, A., Ghafari Gousheh, M., Piri, J., Amin, S. and Han, D. "Evaporation estimation using artificial neural networks and adaptive neuro-fuzzy inference system techniques", Advances in Water Resources, 32(1), pp. 88-97 (2009).

42. Parsaie, A. and Haghiabi, A.H. "Computational modeling of pollution transmission in rivers", Applied Water Science, pp. 1-10 (2015). DOI:10.1007/s13201015-0319-6

\section{Biography}

Amir Hamzeh Haghiabi is an Associate Professor in the Water Engineering at the Lorestan University, Lorestan Province, Iran. Dr. Haghiabi received his $\mathrm{PhD}$ in Hydro Structure Engineering (Water engineering) from Shahid Chamran University, Ahvaz in 2005. Dr. Haghiabi's research has focused on sediment transport, river meandering, numerical and physical modeling of the rivers and hydraulic structure. 